\title{
A brief cognitive-behavioural intervention for pain reduces secondary hyperalgesia
}

Article

Accepted Version

Salomons, T. V., Moayedi, M., Erpelding, N. and Davis, K. D. (2014) A brief cognitive-behavioural intervention for pain reduces secondary hyperalgesia. Pain, 155 (8). pp. 14461452. ISSN 0304-3959 doi:

https://doi.org/10.1016/j.pain.2014.02.012 Available at https://centaur.reading.ac.uk/48391/

It is advisable to refer to the publisher's version if you intend to cite from the work. See Guidance on citing.

Published version at: http://www.sciencedirect.com/science/article/pii/S0304395914000876

To link to this article DOI: http://dx.doi.org/10.1016/j.pain.2014.02.012

Publisher: Elsevier

All outputs in CentAUR are protected by Intellectual Property Rights law, including copyright law. Copyright and IPR is retained by the creators or other copyright holders. Terms and conditions for use of this material are defined in the End User Agreement.

\section{www.reading.ac.uk/centaur}

\section{CentAUR}

Central Archive at the University of Reading 
Reading's research outputs online 


\title{
A brief cognitive-behavioural intervention for pain reduces secondary hyperalgesia
}

\author{
Tim V. Salomons ${ }^{\mathrm{a}, \mathrm{b}, \mathrm{c}}$, Massieh Moayedi ${ }^{\mathrm{a}, \mathrm{d}, \mathrm{e}}$, Nathalie Erpelding ${ }^{\mathrm{a}}$, Karen D. Davis ${ }^{\mathrm{a}, \mathrm{d}, \mathrm{f}, *}$ \\ ${ }^{a}$ Division of Brain, Imaging and Behaviour-Systems Neuroscience, Toronto Western Research Institute, Toronto, Ontario, Canada \\ ${ }^{\mathrm{b}}$ Department of Psychiatry, University Health Network, Canada

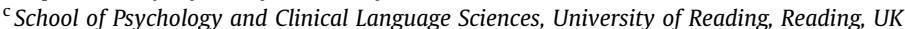 \\ ${ }^{\mathrm{d}}$ Institute of Medical Science, University of Toronto, Toronto, Ontario, Canada \\ e Department of Neuroscience, Physiology and Pharmacology, University College London, London, UK \\ ${ }^{\mathrm{f}}$ Department of Surgery, University of Toronto, Toronto, Ontario, Canada
}

Sponsorships or competing interests that may be relevant to content are disclosed at the end of this article.

\section{A R T I C L E I N F O}

\section{Article history:}

Received 24 September 2013

Received in revised form 24 January 2014

Accepted 18 February 2014

Available online $\mathrm{xxxx}$

\section{Keywords:}

Allodynia

Catastrophizing

CBT

Secondary hyperalgesia

Unpleasantness

\begin{abstract}
A B S T R A C T
Repeated exposure to pain can result in sensitization of the central nervous system, enhancing subsequent pain and potentially leading to chronicity. The ability to reverse this sensitization in a top-down manner would be of tremendous clinical benefit, but the degree that this can be accomplished volitionally remains unknown. Here we investigated whether a brief $(\sim 5 \mathrm{~min})$ cognitive-behavioural intervention could modify pain perception and reduce central sensitization (as reflected by secondary hyperalgesia). In each of 8 sessions, 2 groups of healthy human subjects received a series of painful thermal stimuli that resulted in secondary hyperalgesia. One group (regulate) was given brief painfocused cognitive training at each session, while the other group (control) received a non-pain-focused intervention. The intervention selectively reduced pain unpleasantness but not pain intensity in the regulate group. Furthermore, secondary hyperalgesia was significantly reduced in the regulate group compared with the control group. Reduction in secondary hyperalgesia was associated with reduced pain catastrophizing, suggesting that changes in central sensitization are related to changes in pain-related cognitions. Thus, we demonstrate that central sensitization can be modified volitionally by altering pain-related thoughts.
\end{abstract}

(C) 2014 International Association for the Study of Pain. Published by Elsevier B.V. All rights reserved.

\section{Introduction}

The famed case reports of Beecher [4] describe soldiers who are badly wounded but report no pain until safely out of harm's way. Under other conditions, seemingly modest stimuli can evoke intense pain. These observations exemplify the intriguing disconnect that can exist between nociception and pain. One mechanism thought to contribute to this discrepancy is central sensitization in which the gain of the central nervous system is increased, resulting

\footnotetext{
* Corresponding author at: Division of Brain, Imaging and Behaviour-Systems Neuroscience, Toronto Western Research Institute, Toronto Western Hospital University Health Network, 399 Bathurst St, Room MP14-306, Toronto, Ontario M5T 2S8, Canada. Tel.: +1 416603 5662; fax: +1 4166035745.

E-mail address: kdavis@uhnres.utoronto.ca (K.D. Davis).
}

in increased pain [46] and likely contributing to many chronic pain conditions $[1,10,46]$.

Central sensitization is commonly experience-dependent [22], occurring as a result of plasticity after injury. Although individuals may have limited volitional control over the nociceptive input contributing to this sensitization, they may exert top-down control over cognitive and affective responses, which might in turn exert descending control on incoming signals. Thus, an intriguing and clinically relevant question is whether training individuals to alter their cognitive and affective response to nociceptive input might mitigate or reverse central sensitization. Central sensitization can be modified by the cognitive and affective context in which pain occurs, as demonstrated by the association between sensitization and catastrophizing [11,16,19,29], expectation of analgesia [17], and emotional state $[29,30,32]$. The degree to which training can enhance this cognitive modulation and bring central sensitization under volitional control remains unknown, however. These 
previous studies consistently demonstrate that negative emotions and pain-related cognitions are associated with increased central sensitization. Therefore, we hypothesized that cognitive training that reduced negative cognitions and emotions associated with pain would be associated with reduced sensitization. Towards this end, we developed a brief intervention based on cognitive behavioural therapy (CBT) [2], a psychotherapeutic intervention that targets maladaptive cognitions towards the goal of reducing negative affect. CBT has been successfully adapted to treat pain $[38,39,45]$.

Secondary hyperalgesia is a form of central sensitization in which pain sensitivity is enhanced beyond the site of injury. Originally attributed to sensitization of spinal cord dorsal horn neurons, regions higher in the neuraxis, including the periaqueductal gray (PAG) and rostral ventromedial medulla (RVM) have also been shown to contribute to the inception and maintenance of secondary hyperalgesia [40]. Cortical areas involved in top-down regulatory processes can modulate these brain stem regions both directly and through connections with limbic regions, such as the nucleus accumbens, hypothalamus, or amygdala [15]. Neuroimaging studies have demonstrated cortical involvement in pharmacological and placebo modulation of secondary hyperalgesia [34], providing a plausible mechanism through which secondary hyperalgesia can be modulated by altering pain-related cognitions. It is challenging, however, to acquire behavioural evidence to demonstrate how cognitive training might alter secondary hyperalgesia, because of the difficulty in quantifying injury-related nociceptive input in clinical settings where such interventions commonly occur.

To address this issue, we designed a novel experimental paradigm to determine whether a brief course of CBT could reduce secondary hyperalgesia and affective responses to prolonged experimental heat pain. Given CBT's emphasis on pain-related cognitions and emotions, we hypothesized that the effects of this intervention would be specific to the unpleasantness of pain.

\section{Methods}

\subsection{Subjects}

Forty-one healthy subjects provided informed consent to procedures approved by the University Health Network research ethics board. Subjects were prescreened for chronic pain, psychiatric disorders, use of medications, and medical conditions that would affect pain response. Two subjects withdrew and 5 were excluded for technical reasons, leaving 34 subjects (age range 21-38 years) who were randomized into either an active (ie, pain-focused) treatment (regulate group, $n=17,8$ women) or nonactive (ie, non-painfocused) treatment (control, $n=17,8$ women) group. Each subject underwent 10 experimental sessions over 21 days including initial and final sessions (for thermal thresholds and questionnaires) and 8 test sessions (Fig. 1). The 8 sessions occurred over a total of 10 to 19 days (mean 13.2 days, standard error 1.9 )

\subsection{Thermal detection and pain thresholds}

Thermal stimuli were delivered to the left volar forearm with a $30 \times 30 \mathrm{~mm}$ Peltier thermode (TSA-II, Medoc Ltd, Israel). To determine warmth detection thresholds, we used a standard ramp protocol provided with Medoc software. Subjects were instructed to press a button when they felt a warm sensation (baseline temperature $32^{\circ} \mathrm{C}$, ramp rate $1^{\circ} \mathrm{C} / \mathrm{s}$, negligible interstimulus interval [ISI], average of 4 trials). To determine heat pain thresholds, subjects were instructed to press the button when the temperature became painful (baseline temperature $32^{\circ} \mathrm{C}$, ramp rate $1^{\circ} \mathrm{C} / \mathrm{s}, 30 \mathrm{~s}$ ISI, final 3 of 4 trials used).

\subsection{Determination of intensity of experimental stimuli}

We used an iterative procedure to determine individualized levels of pain. We gave a series of $8 \mathrm{~s}$ stimuli, beginning at heat pain threshold $+1{ }^{\circ} \mathrm{C}$. Subjects rated pain intensity and unpleasantness on a 0 to 10 numeric rating scale (NRS; for intensity: $0=$ no pain, $10=$ most intense pain imaginable; for unpleasantness: $0=$ not unpleasant, $10=$ extremely unpleasant). The distinction between unpleasantness and intensity was explained using instructions adapted from Price et al. [28]. Stimuli were reduced $0.5^{\circ} \mathrm{C}$ if it was intolerable and increased by $0.5^{\circ} \mathrm{C}$ if intensity or unpleasantness were $<6$, until a tolerable temperature $<50^{\circ} \mathrm{C}$ and rated $\geqslant 6$ / 10 on 6 consecutive trials was found. The temperature determined in this session was used in all subsequent sessions.

\subsection{Experimental protocol and cognitive training}

Subjects received forty-five 8-s noxious heat stimuli (30 s ISI) during each of eight $1 \mathrm{~h}$ test sessions (Fig. 1). Every 15 trials, subjects rated stimulus intensity and unpleasantness (0-10 NRS). Within-session ratings were averaged and used to analyze between-session changes. To check whether there was a significant within session variance in these measurements, we conducted an analysis in which we included Measurement as a variable with 3 levels (first, second, and third pain ratings within session).

Before administration of the thermal stimuli, subjects in the regulate group received a brief $(\sim 5 \mathrm{~min})$ session of pain-focused cognitive behavioural training based on an existing treatment manual [38]. They were taught about the relationship between sensory, cognitive, and emotional responses to pain and were trained to reduce their stress response to the painful stimuli by identifying negative cognitions that arose and reappraising their situation to focus on potential benefits of the training (eg, ability to cope with future pain stimuli, financial compensation). They were encouraged to use their training to cope with the painful experimental stimuli. Subjects in the control group were trained in interpersonal effectiveness [23] after the pain stimuli. This training focused on managing the demands of others by effectively balancing goals and expectations and communicating assertively but respectfully with others. Given that investigation of the effects of cognitive training on central sensitization is relatively novel, we sought to determine whether such training had any effect on secondary hyperalgesia rather than to compare it directly to another active psychotherapeutic treatment. Thus, the therapeutic intervention given to the control group was designed to control for general and non-pain-specific effects of a psychotherapeutic intervention (eg, global changes in mood) and not to encourage attempts to cognitively regulate the pain stimuli. Therefore, no link between the training and the painful stimuli was explicitly made and the training was administered after the pain stimuli. Both treatments were administered by an individual (TVS) with graduate training in clinical psychology and equivalent experience administering each treatment. The full text of both interventions administered is available online as Supplemental material.

\subsection{Self-report measures}

Subjects completed the Dysfunctional Attitude Scale (DAS) [44], NEO Five-Factor Inventory (NEO-FFI) [8], and Coping Strategies Questionnaire [31] at the initial visit. Subjects completed the trait version of the Pain Catastrophizing Scale (PCS) [37], Beck depression inventory (BDI) [3], and Spielberger State/Trait Anxiety Inventory (STAI) [36] at the initial and final sessions. Participants rated the degree to which they found the training material novel ("The material was new to me") and useful ("I learned skills which will be useful to me in other contexts") and the degree to which they 


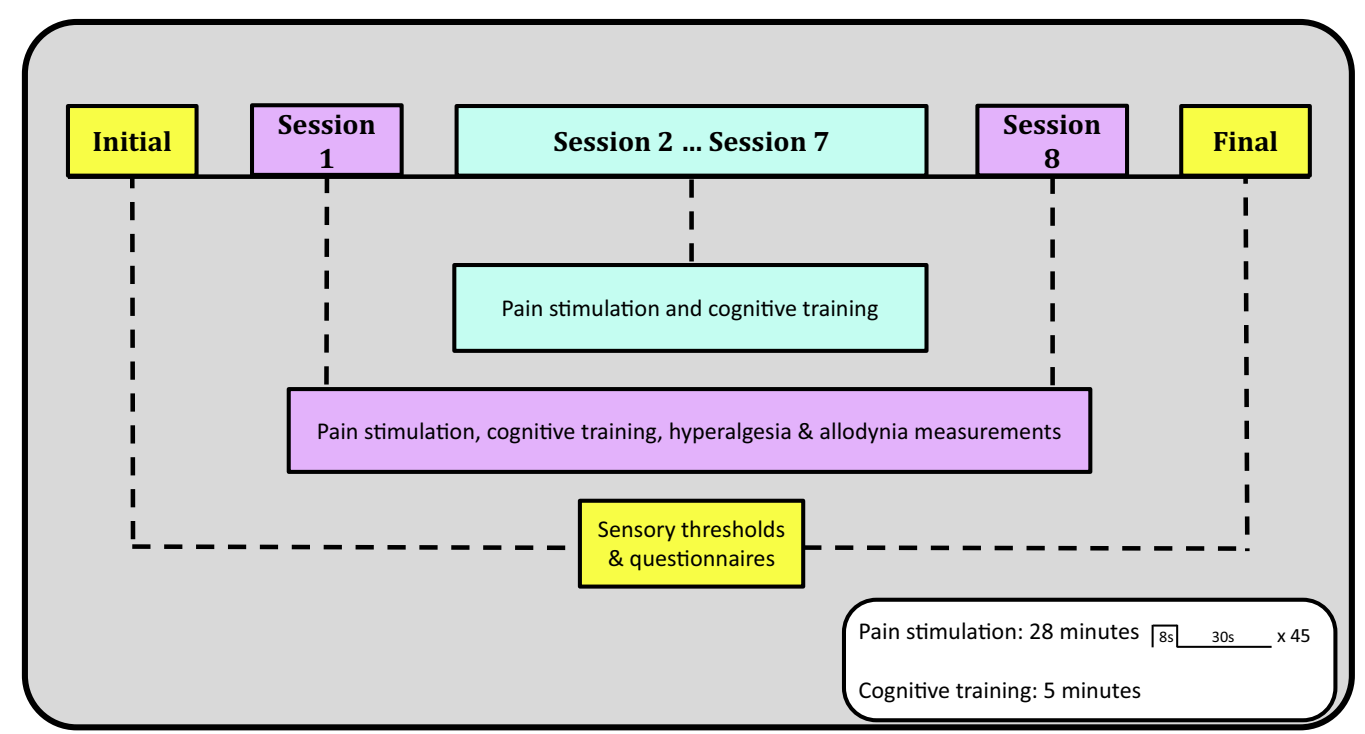

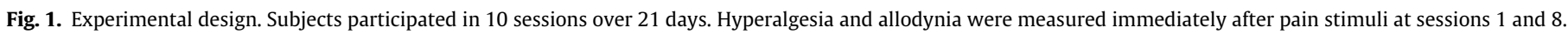
Warmth detection thresholds; heat pain thresholds; and questionnaires were measured at initial and final sessions.

used them outside the training sessions ("I practiced the skills outside the lab") on a 5-point Likert scale.

\subsection{Secondary hyperalgesia and allodynia measurement}

The areas of secondary hyperalgesia and allodynia (pain evoked by a nonnociceptive stimulus) were measured immediately after the last pain stimulus at sessions 1 and 8 by an individual (NE) blinded to group assignment. Measurement was conducted on the basis of previously published work [25]. The borders of secondary hyperalgesia were delineated using punctate mechanical stimuli (256 mN von Frey filament) delivered to the volar forearm distal to the stimulus site (wrist, elbow, side of arm) and moved in $0.5 \mathrm{~cm}$ increments along 8 orthogonal trajectories from well outside the hyperalgesic region towards the stimulation site until the subject reported an increase in pain intensity. Subjects were instructed to indicate the moment they felt an increased pinprick sensation (relative to the pinprick sensation they experienced at the more distal region). As soon as they felt a change in sensation, the stimulation was stopped and the exact location was marked. Allodynia was assessed using a brush stimulus along the same trajectories. The areas of hyperalgesia and allodynia were calculated by transcribing the data points from each trajectory to measured graph paper (with $1 \mathrm{~mm}^{2}$ resolution) to obtain surface area. These calculations were conducted without knowledge of group assignment.

\subsection{Statistical analyses}

Our first hypothesis was that the CBT intervention would reduce secondary hyperalgesia. To test this hypothesis, we used a mixed model analysis of variance (ANOVA), with Group (control vs regulate) as a between-subject variable and Session (1 vs 8) as a within-subject variable. To test our second hypothesis-that the CBT intervention would specifically reduce pain unpleasantnesswe again entered Group as a between-subject variable and Session as a within-subject variable into a mixed model ANOVA along with another within-subject variable, Rating Type (Pain Intensity vs Pain Unpleasantness). To ensure that measurement of pain perception did not significantly vary within sessions, we also entered Measurement (within-session measurements $1-3$ ) as a within-subject variable for each Rating type. To understand the effects that drove the significant interactions, we then followed these analyses up by examining simple main effects. For simple main effects, betweensubjects analysis (of Group) were conducted using a 1-way ANOVA and within-subjects effects (of Session and Rating Type) were conducted by paired $t$ tests (IBM, Armonk, NY). Correlations were compared by a Fisher r-to-z transformation (Vassar stats tool http:// vassarstats.net/rdiff.html). Analyses were thresholded at $P<.05$.

\section{Results}

\subsection{Pain-specific intervention selectively reduced pain unpleasantness}

In line with our prediction, the CBT intervention differentially affected pain intensity and unpleasantness, as evidenced by a significant Session $\times$ Group $\times$ Rating interaction $\left(F_{1,32}=4.32, P<.05\right)$ (Fig. 2). To determine whether this was driven by selective reduction in unpleasantness in the CBT group, we examined Group $\times$ Session interactions for each Rating Type separately. There was a significant Group $\times$ Session interaction for unpleasantness ratings $\left(F_{1,32}=4.93, P<.05\right)$ but not intensity ratings $\left(F_{1,32}=1.8, P=.2\right)$. The pain-focused cognitive training reduced pain unpleasantness ratings by $58 \%$ (mean \pm standard error [SE] $6.5 \pm 0.5$ to $3.1 \pm 0.5$ ), whereas the nonpain training induced a $31 \%$ reduction in pain unpleasantness in the control group (mean \pm SE $6.5 \pm 0.4$ to $4.5 \pm 0.5$ ). The pain intensity ratings decreased by $38 \%$ in the regulate group (mean \pm SE $7.2 \pm 0.4$ to $4.5 \pm 0.5$ ) and by $28 \%$ in the control group (mean \pm SE $6.8 \pm 0.2$ to $4.9 \pm 0.4)$. At Session 1 , there was no group difference for pain intensity $\left(F_{1,32}=0.47, P=.5\right)$ or pain unpleasantness $\left(F_{1,32}=0.01\right.$, $P=.94)$. At Session 8 , there was no significant Group difference for pain intensity $\left(F_{1,32}=0.46, P=.5\right)$ but a marginally significant Group difference in pain unpleasantness $\left(F_{1,32}=4.03, P=.05\right)$. Both groups rated the stimuli as less intense and less unpleasant after 8 training sessions $\left(F_{1,32}=72.72, P<.05\right)$, with significant pre- to postintervention reductions in pain threshold (Table 1 ), indicating a habituation effect across sessions.

There were no Group $\times$ Measurement $\times$ Session interactions for intensity $\left(F_{2,64}=0.47, P=.63\right)$ or unpleasantness $\left(F_{2,64}=0.03\right.$, $P=.97)$ indicating that the intervention did not significantly alter the pattern of pain perception reporting within session. 

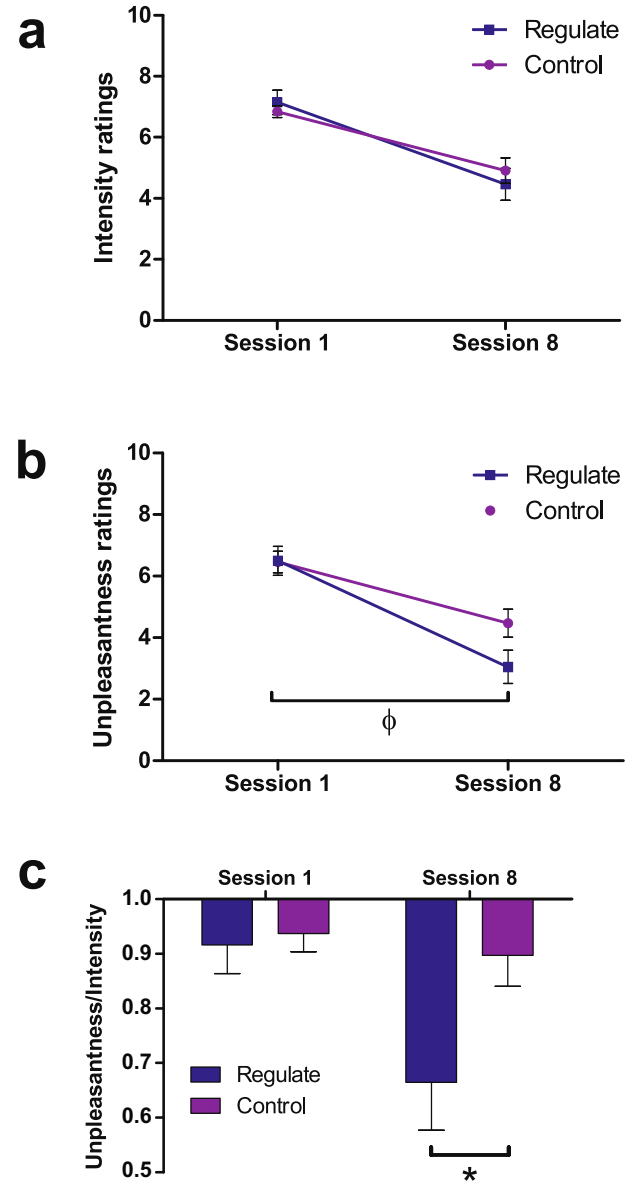

Fig. 2. Significant Group $\times$ Session $\times$ Ratings type interaction. Pain intensity was reduced equally in both groups (A), but regulate group had significantly greater reduction in pain unpleasantness after intervention $(\Phi$ denotes significant Group $\times$ Session $\times$ Ratings interaction, $\left.F_{1,32}=4.32, P<.05\right)(B)$. Relative reduction in unpleasantness (relative to intensity) in regulate group is evident from ratio of unpleasantness/intensity by Session and Group $\left({ }^{*} P<.05\right)(\mathrm{C})$.
Measurement $\times$ Group $\times$ Rating Type interactions were not significant at sessions $1\left(F_{2,64}=0.37, P=.7\right)$ or $8\left(F_{2,64}=1.37, P=.27\right)$. Measurement $\times$ Group and Measurement $\times$ Session interactions were also not significant for intensity or unpleasantness. Because of the lack of interaction with group or session, Measurement effects are not discussed further.

\subsection{Pain-specific intervention reduced secondary hyperalgesia}

There was secondary hyperalgesia on the volar forearm in all but one subject in both groups after the 45 painful stimuli. In line with our hypothesis, there was a significant difference between the effects of the CBT intervention and the control intervention on secondary hyperalgesia, as evidenced by a significant Group $\times$ Session interaction $\left(F_{1,32}=5.9, P<.05\right.$; Fig. $\left.3 \mathrm{~b}\right)$. There was a significant and pronounced $(38 \%)$ reduction in secondary hyperalgesia between the 2 sessions in the regulate group but not in the control group (which had an $8 \%$ increase) (Table 1 ).

Allodynia on the volar forearm was observed less consistently and across a smaller area than secondary hyperalgesia (21 of 34 subjects at session 1,18 of 34 subjects at session 8). There was no significant change between sessions in either group (Table 1 ).

Session $\times$ Group interactions were not significant for allodynia $\left(F_{1,32}=0.53, P=.47\right)$, warmth detection threshold $\left(F_{1,32}=0.59\right.$, $P=.45)$, heat pain threshold $\left(F_{1,32}=0.28, P=.6\right)$, PCS score $\left(F_{1,32}=0.77, P=.39\right)$, and depression $\left(F_{1,32}=0.12, P=.73\right)$. There were no significant reductions in either group in any of these variables (Table 1).

Change in secondary hyperalgesia was significantly correlated with change in PCS within the regulate group $(r=0.56, P<.05$, Fig. 3d) but not in the control group $(r=0.27, P=.31)$. These correlations were not significantly different from each other (Fisher $r$ to-Z transformation, $Z=0.92, P=.36$ ), so no interaction effect should be inferred. Secondary hyperalgesia change was not significantly correlated with changes in pain intensity $(r=0.11, P=.68$ for regulate; $r=-0.09, P=.74$ for control) or pain unpleasantness $(r=0.08, P=.77$ for regulate, $r=-0.03, P=.92$ for control).

Table 1

Psychophysical and behavioural data. ${ }^{a}$

\begin{tabular}{|c|c|c|c|c|c|}
\hline Condition and group & & First measurement & Final measurement & $T$ & $P$ \\
\hline \multirow[t]{3}{*}{ Hyperalgesia $\left(\mathrm{cm}^{2}\right)$} & Regulate & $48.0(7.01)$ & $29.8(7.31)$ & 3.66 & $<.01$ \\
\hline & Control & $45.0(6.29)$ & $48.5(8.80)$ & -0.47 & .65 \\
\hline & $F(P)$ & $0.10(.75)$ & $2.67(.11)$ & & \\
\hline \multirow[t]{3}{*}{ Allodynia $\left(\mathrm{cm}^{2}\right)$} & Regulate & $5.3(2.54)$ & $4.8(2.24)$ & 0.39 & .7 \\
\hline & Control & $7.1(2.29)$ & $9.6(4.26)$ & -0.64 & .53 \\
\hline & $F(P)$ & $0.27(.61)$ & $1.00(.33)$ & & \\
\hline \multirow[t]{3}{*}{ Pain threshold $\left({ }^{\circ} \mathrm{C}\right)$} & Regulate & $46.2(0.77)$ & $48.9(0.22)$ & -4.03 & $<.01$ \\
\hline & Control & $46.0(0.68)$ & $48.0(0.49)$ & -3.6 & $<.01$ \\
\hline & $F(P)$ & $0.05(.83)$ & $2.3(.14)$ & & \\
\hline \multirow[t]{3}{*}{ Warmth detection threshold $\left({ }^{\circ} \mathrm{C}\right)$} & Regulate & $36.2(0.71)$ & $38.0(1.05)$ & -1.34 & .2 \\
\hline & Control & $35.4(0.38)$ & $36.1(0.72)$ & -1.08 & .3 \\
\hline & $F(P)$ & $1.04(.31)$ & $2.3(.14)$ & & \\
\hline \multirow[t]{3}{*}{ PCS } & Regulate & $14(2.2)$ & $11(2.0)$ & 1.6 & .13 \\
\hline & Control & $16(1.9)$ & $16(2.1)$ & 0.32 & .75 \\
\hline & $F(P)$ & $0.78(.39)$ & $2.01(.17)$ & & \\
\hline \multirow[t]{3}{*}{ Depression (BDI total) } & Regulate & $5(1.1)$ & $4(0.9)$ & 1.13 & .28 \\
\hline & Control & $5(0.9)$ & $4(1.1)$ & 0.61 & .55 \\
\hline & $F(P)$ & $0.03(.87)$ & $0.03(.87)$ & & \\
\hline \multirow[t]{3}{*}{ Anxiety (STAI total) } & Regulate & $33(1.5)$ & $31(2.1)$ & 0.87 & .4 \\
\hline & Control & $30(1.8)$ & $29(1.5)$ & 1.28 & .22 \\
\hline & $F(P)$ & $0.09(.35)$ & $0.74(.4)$ & & \\
\hline
\end{tabular}

PCS, pain catastrophizing scale; BDI, Beck Depression Index; STAI, State-Trait Anxiety Index.

${ }^{\text {a }}$ Data are presented as mean (standard error) group data. Paired $t$ tests were used to compare sessions within groups. One-way analyses of variance were used to compare groups within sessions. 
a

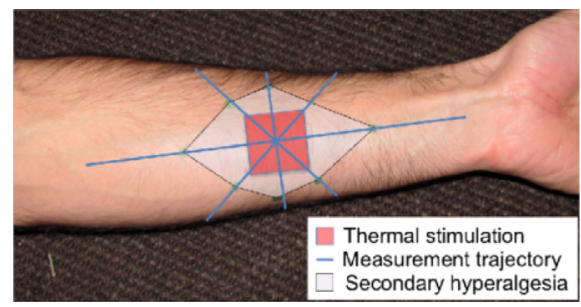

b
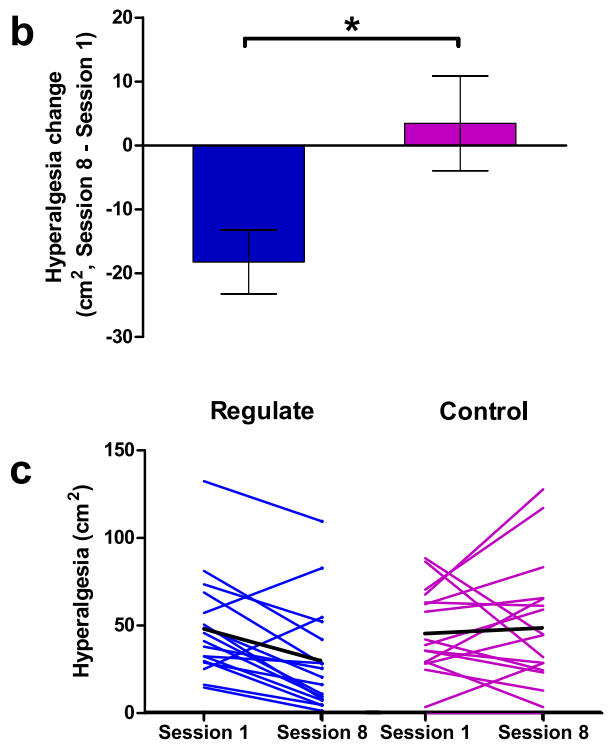

d

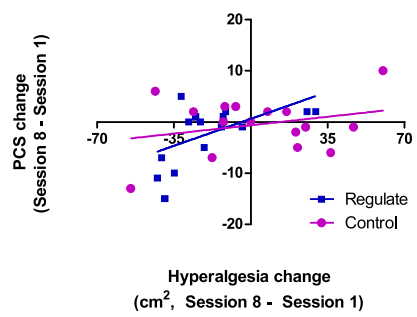

Fig. 3. Secondary hyperalgesia is reduced by cognitive intervention. (A) Example of zone of mechanical secondary hyperalgesia as delineated along 8 orthogonal measurement trajectories. (B) Difference scores for secondary hyperalgesia $\left({ }^{*} P<.05\right)$ for regulate and control groups. Error bars represent standard error. (C) Individual subjects' change in secondary hyperalgesia by group. (D) Relationship between absolute change in secondary hyperalgesia and pain catastrophizing. Correlation was significant in regulate group $(r=0.56, P<.05)$ but not in control group $(r=0.27, P=.31)$.

\subsection{No group differences at baseline}

There was no significant group difference in the temperature chosen and administered throughout the trial $\left(F_{1,32}=0.44\right.$, $P=.51,48.3 \pm 0.28^{\circ} \mathrm{C}[$ mean $\pm \mathrm{SE}]$ for regulate group, $47.9 \pm 0.45^{\circ} \mathrm{C}$ for control group). There were no baseline differences in warmth detection threshold, heat pain threshold, allodynia, or secondary hyperalgesia (Table 1). There was also no significant group difference in preexisting pain-related attitudes (PCS), coping strategies (CSQ), personality factors (NEO-FFI), depression (BDI), anxiety (STAI), and dysfunctional attitudes (DAS) (all $P>.05$ ).

\subsection{Interventions matched in subject participation and non-pain- related benefits}

The 2 groups did not differ in the degree to which they viewed the therapeutic intervention as novel $\left(F_{1,32}=3.2, P=.08\right)$ or useful outside of the laboratory $\left(F_{1,32}=2.10, P=.16\right)$ or in the degree to which they practiced the skills they were taught $\left(F_{1,32}=0.36\right.$, $P=.56)$. This demonstrates that both treatments were considered beneficial and that effects observed were not due to non-pain-specific differences in the treatments.

There were no significant main effects of Sex or Group $\times$ Sex interactions in any of the dependent measures examined.

\section{Discussion}

Central sensitization contributes to the pathophysiology of many clinical pain conditions $[1,10,46]$. The mechanisms through which ongoing nociceptive input enhances central sensitization is well studied [22], but little is known about how individuals might volitionally and endogenously attenuate central sensitization by altering their cognitive and affective response to ongoing noxious input. To elucidate these processes, we designed a novel paradigm in which participants were exposed to repeated thermal pain in 8 sessions, with half of the participants receiving an intervention based on CBT [38]. We report 2 important findings.

The first key finding is that the cognitive intervention specifically altered the affective, but not sensory, dimension of pain. The groups had a similar reduction in pain intensity over the experimental sessions, but the regulate group had a significantly greater reduction in pain unpleasantness ratings. This selective decline in pain unpleasantness is consistent with the focus of CBT on managing pain-related thoughts and feelings.

The second important and novel finding is that cognitive intervention reduced secondary hyperalgesia, a proxy for central sensitization, in the regulate group. Individuals with the greatest reduction in secondary hyperalgesia also had the largest reductions in pain catastrophizing. Thus, we have demonstrated that training individuals to alter their cognitive response to pain can reduce central sensitization and that these changes are associated with changes in pain-related beliefs.

Although CBT is directly aimed at altering pain-related thoughts and emotions, the effects of these alterations on the central processing of incoming sensory signals are not well understood. Melzack and Wall's [24] classic gate control theory proposed that descending signals from the brain could modulate incoming nociceptive signals at the spinal level, providing a plausible mechanism by which thoughts and feelings might influence pain processing directly. We now know that supraspinal regions such as PAG and RVM can facilitate or inhibit spinal processing of nociceptive input and that upstream, this pathway is connected to brain regions involved in cognition and affect such as the amygdala, anterior cingulate, and prefrontal cortices [15]. The role of RVM-mediated descending facilitation in secondary hyperalgesia has been demonstrated, with facilitation of pain outside of injured tissue blocked by transection of the spinal cord and chemical block of RVM $[20,41]$. Secondary hyperalgesia may be limited by tonic descending inhibition, but with prolonged nociceptive input, descending facilitation might become more prominent [43]. Therefore, in this study, prolonged nociceptive input may have induced facilitation outside the stimulation area, which was subsequently reduced or counteracted by increased inhibitory signals.

Animal and human studies indicate an interaction of brain stem regions involved in descending control with cortical regions involved in modulation of cognition and emotion. This provides a plausible mechanism by which altering cognitive responses to pain might alter the balance of descending inhibition and facilitation. Neuroimaging studies of top-down modulation of pain demonstrated coactivation of PAG with cortical regions such as ventromedial prefrontal cortex when pain is altered by cognitive manipulations [6,12,26,33,42]. Furthermore, the dorsal horn's involvement in placebo analgesia suggests a link between expectation and modulation of ascending nociceptive signals [13]. 
Behavioural evidence also supports the possibility that central sensitization and descending pain control can be altered on the basis of cognitive and/or affective context in which pain occurs. For example, expectation of hyperalgesia can block analgesic effects of counterirritation [17], and emotional manipulations can alter self-reported pain perception and nociceptive flexion reflex in a valence-specific manner [30], suggesting descending inhibition and facilitation of spinal responses. There is also evidence that relaxation training alters nociceptive flexion reflex [14]. Consistent with our finding that changes in secondary hyperalgesia co-occurred with, but did not correlate with, changes in perceived pain unpleasantness, affective modulation of pain self-report and spinal reflexes can be dissociated under different cognitive conditions [29] via separate neural mechanisms [32]. There are also individual differences in the degree to which changes in sensitization and pain perception co-occur [9].

Individual differences in psychological factors such as catastrophizing can alter central sensitization/descending control $[11,16,18,19,29]$, leading to the hypothesis that treatments that reduce catastrophizing might also reduce central sensitization [18]. Our study provides support for this hypothesis because individuals whose catastrophizing was reduced by the cognitive intervention had the greatest reduction in secondary hyperalgesia. However, there was no group difference in the reduction of catastrophizing and no significant difference in the relationship between changes in catastrophizing and secondary hyperalgesia. This finding limits the inferences that can be made about the effectiveness of the intervention in reducing catastrophizing. One possible explanation is that the change that occurred was in state catastrophizing (ie, catastrophizing specific to the pain stimuli presented) and that the measure of catastrophizing used captured only a portion of the relevant variance. The inability to distinguish changes to state and trait catastrophizing is a limitation of the study. An alternative explanation for the lack of group differences is that some individuals in the control group had reductions in both catastrophizing and secondary hyperalgesia without intervention. Elucidating which individuals respond maximally to cognitive interventions and which might simply improve over time without intervention might therefore improve our understanding of how to efficiently apply these treatments.

A laboratory-based paradigm such as the one used here offers distinct advantages for understanding mechanisms of cognitive interventions. Unlike clinical studies, the amount of nociceptive input can be controlled, eliminating confounding elements due to individual differences in peripheral pathology, which are often poorly understood. Previous work has demonstrated consistent but moderate effects of CBT in chronic pain populations [45]. Improvement in outcomes is hampered by limited understanding of the processes by which successful treatment occurs and lack of appropriate measures to understand these processes [45]. Our study suggests that in addition to commonly studied outcome measures like depression and disability, modulation of central sensitization might be an additional benchmark for examining the effectiveness of these interventions. Our design allows for manipulation of nociceptive input and direct measurement of secondary hyperalgesic responses and their relationship to sensory, affective, and cognitive responses to pain, potentially providing improved understanding of how these treatments work and whom they work for.

We also note that this study was an exploratory investigation of whether cognitive training can affect sensitization; it was not designed to identify the specific components of the training that contribute to the observed effect. The psychotherapeutic intervention given to the control group was intended to control only for general effects of psychotherapy (eg, changes in mood) beyond the experimental context. Therefore, we did not match the 2 groups in terms of their ability to apply what they learned during the experience of pain and placed the control intervention after the pain stimuli to explicitly avoid use of the skills taught in the control intervention during pain. This design places limitations on the interpretations of the findings as follows. First, because the study was not designed to compare 2 active treatments for pain, it should not be concluded that CBT is superior to other psychotherapeutic interventions in terms of the effects observed. Second, it is possible that the groups differed in terms of effects not specific to CBT, such as distraction during pain or differential experimenter contact. It should be noted, however, that any differences in training were present at both session 1 and session 8 , making it unlikely that such differences would drive the significant Session $\times$ Group interactions that constitute the key findings in this paper. Nevertheless, the CBT intervention used here consisted of many different elements, including reduction of negative thoughts and focus on positive goals. Further study is needed to isolate specific aspects of therapeutic intervention that alters central sensitization.

Much is known about how maladaptive plasticity gives rise to central sensitization and how central sensitization contributes to pain disorders. Less is known about how this plasticity can be harnessed and reversed volitionally. If prolonged nociceptive input alters the balance of descending inhibition and facilitation, leading to chronicity [27], then mitigating or reversing this plasticity at an early stage might prevent chronification of pain. Here we demonstrate reduction in experience-induced secondary hyperalgesia after a brief cognitive-behavioural intervention. These findings show how alteration of pain-related cognitive and affective responses can reduce centrally mediated pain responses, leading to the intriguing possibility that such intervention might reduce pain chronicity. Recent work demonstrates that CBT alters both functional activation [21] and brain structure [35] in regions involved in cognitive modulation and descending control of pain in chronic pain populations, suggesting that plasticity that underlies the observed reductions in central sensitization could be similar to that present in chronic pain. The time course of such changes is unclear. CBT can have long-term effects over variables such as anxiety, depression, perceived control, and functional disability [5]. Bushnell et al. [7] suggested the neural bases that underlie these types of cognitive and affective deficits may overlap with pain modulatory systems, suggesting that the time course of central sensitization changes might be similar. Nevertheless, further research is needed to delineate the time course of the effects observed here and the likelihood that reductions in central sensitization might represent a long-lasting benefit of pain focused cognitive training.

\section{Conflict of interest statement}

The authors report no conflict of interest.

\section{Acknowledgements}

This work was supported by the Canadian Institutes of Health Research and the Canada Research Chair program. TVS was funded by a Clinician-Scientist Award from the University of Toronto Centre for the Study of Pain. MM was funded by a CIHR Banting and Best Canada Graduate Scholarship, an Ontario Graduate Scholarship and the CIHR Pain: M2C and Cell Signals Strategic Training in Health Research grants. NE was supported by the Fonds National de la Recherche Luxembourg (PDR-09-023).

\section{Appendix A. Supplementary data}

Supplementary data associated with this article can be found, in the online version, at http://dx.doi.org/10.1016/j.pain.2014.02.012. 


\section{References}

[1] Arendt-Nielsen L, Yarnitsky D. Experimental and clinical applications of quantitative sensory testing applied to skin, muscles and viscera. J Pain 2009;10:556-72.

[2] Beck A. Cognitive therapy of depression. New York: Guilford Press; 1979.

[3] Beck AT, Steer RA, Ball R, Ranieri W. Comparison of beck depression inventories-IA and -II in psychiatric outpatients. J Pers Assess 1996;67:588-97.

[4] Beecher HK. Pain in men wounded in battle. Ann Surg 1946;123:96-105.

[5] Bennett R, Nelson D. Cognitive behavioral therapy for fibromyalgia. Nat Clin Pract Rheumatol 2006;2:416-24.

[6] Bingel U, Lorenz J, Schoell E, Weiller C, Büchel C. Mechanisms of placebo analgesia: rACC recruitment of a subcortical antinociceptive network. PAIN ${ }^{\circledR}$ 2006;120:8-15.

[7] Bushnell MC, Ceko M, Low LA. Cognitive and emotional control of pain and its disruption in chronic pain. Nat Rev Neurosci 2013;14:502-11.

[8] Costa PT, McCrae RR. Bridging the gap with the five-factor model. Personal Disord 2010;1:127-30.

[9] Danziger N, Fournier E, Bouhassira D, Michaud D, De Broucker T, Santarcangelo E, Carli G, Chertock L, Willer JC. Different strategies of modulation can be operative during hypnotic analgesia: a neurophysiological study. PAIN ${ }^{\circledR}$ 1998;75:85-92.

[10] Edwards RR. Individual differences in endogenous pain modulation as a risk factor for chronic pain. Neurology 2005:65:437-43.

[11] Edwards RR, Smith MT, Stonerock G, Haythornthwaite JA. Pain-related catastrophizing in healthy women is associated with greater temporal summation of and reduced habituation to thermal pain. Clin J Pain 2006;22:730-7.

[12] Eippert F, Bingel U, Schoell ED, Yacubian J, Klinger R, Lorenz J, Büchel C. Activation of the opioidergic descending pain control system underlies placebo analgesia. Neuron 2009;63:533-43.

[13] Eippert F, Finsterbusch J, Bingel U, Büchel C. Direct evidence for spinal cord involvement in placebo analgesia. Science 2009;326:404.

[14] Emery CF, Keefe FJ, France CR, Affleck G, Waters S, Fondow MDM, McKee DC France JL, Hackshaw KV, Caldwell DS, Stainbrook D. Effects of a brief coping skills training intervention on nociceptive flexion reflex threshold in patients having osteoarthritic knee pain: a preliminary laboratory study of sex differences. J Pain Symptom Manage 2006;31:262-9.

[15] Fields HL, Basbaum B, Heinricher MM. Central nervous system mechanisms of pain modulation. In: Textbook of pain. New York: Elsevier; 2006. p. 125-42.

[16] George SZ, Wittmer VT, Fillingim RB, Robinson ME. Sex and pain-related psychological variables are associated with thermal pain sensitivity for patients with chronic low back pain. J Pain 2007;8:2-10.

[17] Goffaux P, Redmond WJ, Rainville P, Marchand S. Descending analgesia-when the spine echoes what the brain expects. PAIN ${ }^{\circledR}$ 2007:130:137-43.

[18] Goodin BR, Glover TL, Sotolongo A, King CD, Sibille KT, Herbert MS, CruzAlmeida Y, Sanden SH, Staud R, Redden DT, Bradley LA, Fillingim RB. The association of greater dispositional optimism with less endogenous pain facilitation is indirectly transmitted through lower levels of pain catastrophizing. J Pain 2013;14:126-35.

[19] Granot M, Granovsky Y, Sprecher E, Nir RR, Yarnitsky D. Contact heat-evoked temporal summation: tonic versus repetitive-phasic stimulation. PAIN 2006;122:295-305.

[20] Herrero JF, Cervero F. Supraspinal influences on the facilitation of rat nociceptive reflexes induced by carrageenan monoarthritis. Neurosci Lett 1996;209:21-4.

[21] Jensen KB, Kosek E, Wicksell R, Kemani M, Olsson G, Merle JV, Kadetoff D, Ingvar M. Cognitive behavioral therapy increases pain-evoked activation of the prefrontal cortex in patients with fibromyalgia. PAIN ${ }^{\circledR} 2012 ; 153: 1495-503$.

[22] Ji RR, Kohno T, Moore KA, Woolf CJ. Central sensitization and LTP: do pain and memory share similar mechanisms? Trends Neurosci 2003;26:696-705.
[23] Linehan MM. Skills training manual for treating borderline personality disorder. New York: Guilford Press; 1993.

[24] Melzack R, Wall PD. Pain mechanisms: a new theory. Science 1965;150:971-9.

[25] Pedersen JL, Kehlet H. Secondary hyperalgesia to heat stimuli after burn injury in man. PAIN ${ }^{\circledR} 1998 ; 76: 377-84$.

[26] Petrovic P. Placebo and opioid analgesia-imaging a shared neuronal network. Science 2002;295:1737-40.

[27] Porreca F, Ossipov MH, Gebhart GF. Chronic pain and medullary descending facilitation. Trends Neurosci 2002;25:319-25.

[28] Price DD, McGrath PA, Rafii A, Buckingham B. The validation of visual analogue scales as ratio scale measures for chronic and experimental pain. PAIN ${ }^{\circledR}$ 1983:17:45-56.

[29] Rhudy JL, Martin SL, Terry EL, France CR, Bartley EJ, DelVentura JL, Kerr KL. Pain catastrophizing is related to temporal summation of pain but not temporal summation of the nociceptive flexion reflex. PAIN ${ }^{\circledR} 2011 ; 152: 794-801$.

[30] Rhudy JL, Williams AE, McCabe KM, Nguyen MATV, Rambo P. Affective modulation of nociception at spinal and supraspinal levels. Psychophysiology 2005;42:579-87.

[31] Rosenstiel AK, Keefe FJ. The use of coping strategies in chronic low back pain patients: relationship to patient characteristics and current adjustment. PAIN ${ }^{\circledR}$ 1983; 17:33-44.

[32] Roy M, Piché M, Chen JI, Peretz I, Rainville P. Cerebral and spinal modulation of pain by emotions. Proc Natl Acad Sci U S A 2009;106:20900-5.

[33] Salomons TV, Johnstone T, Backonja MM, Shackman AJ, Davidson RJ. Individual differences in the effects of perceived controllability on pain perception: critical role of the prefrontal cortex. J Cogn Neurosci 2007:19:993-1003.

[34] Seifert F, Bschorer K, De Col R, Filitz J, Peltz E, Koppert W, Maihöfner C. Medial prefrontal cortex activity is predictive for hyperalgesia and pharmacological antihyperalgesia. J Neurosci 2009;29:6167-75.

[35] Seminowicz DA, Shpaner M, Keaser ML, Krauthamer GM, Mantegna J, Dumas JA, Newhouse PA, Filippi CG, Keefe FJ, Naylor MR. Cognitive-behavioral therapy increases prefrontal cortex gray matter in patients with chronic pain. J Pain 2013:14:1573-84.

[36] Spielberger CD, Gorsuch RL, Lushene RE, Vagg PR, Jacobs GA. Manual for the state-trait anxiety inventory. Palo Alto: Consulting Psychologist Press; 1983.

[37] Sullivan MJL, Bishop SR, Pivik J. The pain catastrophizing scale: development and validation. Psychol Assess 1995;7:524-32.

[38] Thorn B. Cognitive therapy for chronic pain: a step-by-step guide. New York: Guilford Press; 2004.

[39] Turk DC, Meichenbaum D, Genest M. Pain and behavioral medicine: a cognitive behavioral perspective. New York: Guilford Press; 1983.

[40] Urban MO, Gebhart GF. Supraspinal contributions to hyperalgesia. Proc Natl Acad Sci U S A 1999;96:7687-92.

[41] Urban MO, Jiang MC, Gebhart GF. Participation of central descending nociceptive facilitatory systems in secondary hyperalgesia produced by mustard oil. Brain Res 1996;737:83-91.

[42] Valet M, Sprenger T, Boecker H, Willoch F, Rummeny E, Conrad B, Erhard P, Tolle TR. Distraction modulates connectivity of the cingulo-frontal cortex and the midbrain during pain-an fMRI analysis. PAIN ${ }^{\circledR} 2004 ; 109: 399-408$.

[43] Vanegas H, Schaible HG. Descending control of persistent pain: inhibitory or facilitatory? Brain Res Brain Res Rev 2004;46:295-309.

[44] Weissman AN, Beck AT. Development and validation of the Dysfunctional Attitude Scale: A preliminary investigation. Paper presented at the meeting of the Association for the Advancement of Behavior Therapy. Chicago; 1978.

[45] Williams AC de C, Eccleston C, Morley S. Psychological therapies for the management of chronic pain (excluding headache) in adults. Cochrane Database Syst Rev 2012;11:CD007407.

[46] Woolf CJ. Central sensitization: implications for the diagnosis and treatment of pain. PAIN ${ }^{\circledR} 2011 ; 152:$ S2-15. 